\title{
Early Childhood Psychological Development in Interacting with New Friends
}

\author{
Simonna Andrejevaité ${ }^{1}$, Edita Špokaite ${ }^{1}$ \\ ${ }^{1}$ Faculty of Human and Social Studies, Mykolas Romeris University, Lithuania
}

\begin{abstract}
The consistency of children's interactions has an impact on their subsequent social growth. It can be shown that children who avoid contact with their peers also exist; children who barely socialize with their friends, choose to be lonely, are reserved, and lack self-confidence. Meanwhile, children can develop the ability to facilitate and sustain social connections, as well as dispute resolution skills such as taking turns playing, negotiating, and even negotiation, by their partnerships with their peers. When engaging in these types of tasks, children often undergo a pattern of synchronization between their comprehension, execution, and desired outcome. Children may create bonds through this experience, and can offer a sense of comfort away from family members.
\end{abstract}

Keywords: Early Childhood, Social Interaction, Psychological Development

Received: March 2, 2021

Revised: May 1, 2021

Accepted: May 17, 2021

\section{Introduction}

Any child can sometimes behave naughty, disrespectful, or exhibit impulsive behaviour. Finally, conflict between parent and infant is unavoidable, beginning at the age of two years and continuing before the child reaches the age of adolescence and desires to pursue identity and try new stuff. This behaviour is discovered to be natural and is a necessary component of the maturation phase. However, certain children exhibit difficult-to-control habits (Hare-Bruun et al., 2011). Parents are urged to get assistance from a psychologist in this situation. Child psychology may ascertain the underlying factors of children's behaviour that deviates from ageappropriate standards (Braet et al., 2014). For instance, brain abnormalities, biology, food issues, family circumstances, and tension. Then, a child specialist will assist you with resolving the current issue.

Children's cognitive maturity requires their capacity to analyze thoughts and feelings. Understanding the underlying causes of specific thoughts and feelings may assist children in managing them. This intricate phase starts in infancy and continues throughout adulthood. Joy, rage, sorrow, and anxiety are the first feelings that will emerge in an infant. Additionally, when a child grows older, he develops the ability to understand and articulate guilt, surprise, pleasure, confidence, and even empathy. And the things that elicit an emotional reaction in a child will alter. Similarly, in how children do it. Managing feelings may be very complicated for certain children. Particularly for temperamental children. A child psychologist can assist you in dealing with an emotionally disturbed child by determining why. The counselor would then search at ways that support children in accepting their emotions and comprehending the connection between their behaviour and their feelings. Behavioral issues with children of this era are typically transient and often correlated with challenging conditions (Biederman, 2005). For instance, the birth of a younger sibling, parental breakup, or a family member's death. Additionally, behavioral disorders may manifest as violent, disruptive, or offensive acts that are out of character with the child's age. Oppositional defiance disorders, conduct disorders, and attention deficit hyperactivity disorder are both examples of common aggressive 
personality disorders (Ollendick et al, 2008). Any of the three conditions exhibits common effects which may result in mood disorders and interpersonal difficulties.

\section{Early Childhood Psychology Development}

This social development is inextricably linked to emotional growth. Children's socialization abilities enable them to participate in meaningful activities with their families, instructors, and classmates, as well as their neighbors (King et al, 2010). This pattern is repeated, and early childhood develops into a critical phase of socialization. One of the partnerships, and perhaps the most important for providing positive opportunities for infants, is the partnership with their parents and other caregivers for the first time. The consistency of this partnership would have an impact on the child's potential social growth. Meanwhile, children can develop the ability to facilitate and sustain social connections, as well as dispute resolution skills such as taking turns playing, negotiating, and even negotiation, by their partnerships with their peers (Raghavendra, et al, 2012).

When engaging in these types of tasks, children often undergo a pattern of synchronization between their comprehension, execution, and desired outcome. Children may create bonds through this experience, and can offer a sense of comfort away from family members. Early childhood refers to an infant that is born before the age of six. This is a formative stage in the development of a child's personality. Additionally, this is the era at which infants undergo accelerated growth and development, and the early years of childhood are critical and central to the growth and development of humans. Since children at this age are curious about the condition of their society and how they may contribute to it. When children join the field of school, they tend to engage with their peers more often, either favorably or negatively (Owen et al, 2008). Children can be seen in four dimensions during the early stages of childhood growth, namely: 1) Children should collaborate with their friends; 2) Children should value their friends' belongings, thoughts, and work; and 3) Children should collaborate with their friends. 4) The era of competent children in childhood is often referred to as the pre-group period.

The foundation for socialization is laid each year by increasing the number of relationships between children and their peers. Kids not only engage with other children more often, they often place a higher premium on social contact with their peers in the school setting. (Eisenberg, 2010). Children who lack self-confidence and children who are unable to communicate effectively with their community will be ostracized, shunned by their environment, and it may be impossible to include friends in play or social activities. However, if a child has strong peer contact abilities, he or she may have more buddies and, as a result, the child's social level will be able to communicate well. Since colleagues play a critical position in social and interpersonal interactions. Where peers are children that are about the same age and maturity stage. Early childhood is included in children's early growth (preschool years aged 3-6 years), implying that as preschoolers encounter the larger social environment, they experience greater difficulties and must cultivate behaviors geared toward addressing these obstacles.

It can be shown that children who avoid contact with their peers also exist; children who barely socialize with their friends, choose to be lonely, are reserved, and lack self-confidence. According to interviews with class instructors, as studying and playing hours started, five children appeared to stay squarely in their seats and engage in limited tasks, listening to the instructor and being quiet, barely conversing with peers and never answering questions. Then, at lunch, the five children appeared to go directly to their parents' house, in contrast to their other mates, who were engaged in a variety of peer-to-peer games (Rudolph, 2010). Children who lack involvement appear to be the guide and deserve extra care so they can serve as a 
comparison point when the kid enters higher education. Class teachers innovate learning strategies both independently and in classes in order to help children's physical, psychological, and social growth (Dean et al, 2014). Personal-social guidance is an attempt to assist individuals in addressing and resolving personal-social issues such as transition, dispute resolution, and partnerships. Social contact is a personal social challenge and it stems from human personal issues such as shyness, a need to be isolated, and a loss of self-confidence, both of which have an effect on their social interactions. The issue of social contact can be addressed by assisting these children in developing strong social interaction abilities, specifically by the use of instructional approaches offered by kindergarten teachers. Guidance and therapy in early childhood provides a variety of resources to support early childhood growth, including data collection, knowledge dissemination, counseling, placement, review, and follow-up.

\section{Early Childhood Social Interaction Problems}

In order to address this issue of social contact, school psychologists incorporate selection programs that assist children in grouping their skills in order to communicate effectively. In kindergarten education, a variety of approaches are used in the learning phase, many of which contribute to the cognitive and affective growth of adolescents. Related to the difficulties encountered by certain children who are unable to communicate socially while also developing the children's social contact abilities. Methods for assisting children in improving their social interaction development in early childhood must be optimally tailored to the child's difficulties and desires. As a result, the classroom instructor has only one tool, namely the project method, for assisting children in interacting with their surroundings, classes, classmates, and instructors. The project approach is intended to assist children who lack the capacity to engage socially in adapting to their school setting.

Development is a process of transformation, and this change is relational rather than quantitative ( Rubin, 2013). On the content level, development is not prioritized. However, in a practical sense. Another concept of growth is the process through which a person or organism progresses toward maturity or maturity that occurs in a systemic, gradual, and consistent manner, both physically and psychologically. Social behaviour encompasses any human behavior that is associated with non-individualism. There are some critical facets of children's social development that must be grasped, showing that as preschoolers engage with peer associations, they share two characteristics. The first is by social interaction, through which children engage in cooperative play or attempt to partake in community events organized by peers. The second concern is the safeguarding of virtual rooms. Specifically, the proclivity of children engaged in an episode of ongoing play exercises to avoid attempts or intervention by other participant children.

Thus, social growth may be described as the attainment of maturity in interpersonal relationships. Can also be viewed as a method of adapting to norms, principles, and traditions: coalescing into a cohesive entity capable of communicating and cooperating. According to Plato, humans are born social creatures, so in order to understand this ability, they must communicate with other humans' environments.

Children's social growth is marked by an involvement in the actions of peers and a rise in a deep desire to be included as a part of a community, and they are disappointed when they are not with their friends (Hart, 2013). The child is no longer content playing alone at home, with relatives, or participating in sports with family members; the child desires to be with peers and will feel sad and unsatisfied if he is not with them. Two or three mates were insufficient for him. Children want to be part of a community and only then can there be sufficient mates to 
interact with and workout with, as well as the ability to offer pleasure. From the time children start school until they reach adolescence, the need to belong to and be embraced by communities increases. As a result, an increasing number of preschoolers are exhibiting psychosocial issues, including social emotional problems such as anxiety, difficulty adapting, difficulty socializing, difficulty withdrawing from parents, unruly children, and violent behaviour. Most often, they manifest in preschool children. Peer relationships have a significant impact on a child's success ( Martin et al, 2011). The child's habit of playing with devices is one of the causes or triggers that may influence their growth.

Parents play a critical role in restricting and tracking their children's use of devices. The child's first world is his or her relatives (Powell et al, 2013). A supportive atmosphere promotes children's growth, while a negative or harmful environment retards children's growth and development. Kids spend the most of their time at home. The family becomes a role model for children in their early years. Early childhood is an excellent model. Gadgets, or in Indonesian, a gadget, is a mechanical device or instrument with a functional intent and function that is purposefully more complex than previously developed technology (Roser, 2016). Gadgets are genuinely magical, smart, and very helpful in a variety of ways, including handling flights, lodging, e-mails, watching movies, looking up addresses or charts, ordering food, and purchasing merchandise. According to Wikipedia, electronics, which include notebooks, iPads, tablets, and smartphones, are technical resources that provide a variety of apps and knowledge about the planet. Additionally, the usage of electronics has a detrimental effect on youth. Due to the simplicity with which children may access different forms of knowledge and technologies, they become sedentary and unable to travel and participate in sports. They would rather stay comfortably in front of the gadget and admire the universe contained inside. They have increasingly forgotten how much fun it is to play alongside their peers and family members. Naturally, this would have a detrimental effect on the welfare and wellbeing of developing children. Additionally, excessive time spent in front of a gadget computer disrupts children's social experiences (Gaskins, 2007). Today's children rely heavily on technology, and as a result, their families rely on technology as well. This technology has a detrimental effect on family communication, making everyday tasks more complicated.

\section{Social Interaction Skills}

Social contact is a partnership between two or more human beings through which one individual's behavior influences, modifies, or strengthens the behaviour of another, or vice versa (McKown et al, 2009). Social contact is a complex social partnership that involves interactions between individuals, groups of individuals, and individuals and groups of individuals. Social contact is a partnership between a person and another individual or an individual and a community in which these entities control, alter, and benefit from one another.

\section{Social Development in Early Childhood}

Individuals of emotional knowledge have a high level of social awareness. Children's capacity to comprehend the external universe may be enhanced by supplying information regarding the social atmosphere of a given place. By the close of puberty, the majority of adolescents are already unhappy with their social growth advancement. And if their growth is natural, this is so. Numerous researches examining the causes of unhappiness identified by young men and women have placed a high premium on social issues.

\section{Conclusion}

Children's social growth is marked by an involvement in the actions of peers and a rise in a deep desire to be included as a part of a community, and they are disappointed when they are 
not with their friends. Social contact is a partnership between two or more human beings through which one individual's behavior influences, modifies, or strengthens the behaviour of another, or vice versa. The consistency of this partnership would have an impact on the child's potential social growth. Meanwhile, children can develop the ability to facilitate and sustain social connections, as well as dispute resolution skills such as taking turns playing, negotiating, and even negotiation, by their partnerships with their peers.

\section{References}

Biederman, J. (2005). Attention-deficit/hyperactivity disorder: a selective overview. Biological psychiatry, 57(11), 1215-1220.

Braet, C., O'Malley, G., Weghuber, D., Vania, A., Erhardt, É., Nowicka, P., ... \& ArdeltGattinger, E. (2014). The assessment of eating behaviour in children who are obese: a psychological approach. A position paper from the European childhood obesity group. Obesity Facts, 7(3), 153-164.

Dean, M., Kasari, C., Shih, W., Frankel, F., Whitney, R., Landa, R., ... \& Harwood, R. (2014). The peer relationships of girls with ASD at school: comparison to boys and girls with and without ASD. Journal of Child Psychology and Psychiatry, 55(11), 1218-1225.

Eisenberg, N., Valiente, C., \& Eggum, N. D. (2010). Self-regulation and school readiness. Early education and development, 21(5), 681-698.

Gaskins, S., Haight, W., \& Lancy, D. F. (2007). The cultural construction of play. Play and development: Evolutionary, sociocultural, and functional perspectives, 179-202.

Hare-Bruun, H., Nielsen, B. M., Kristensen, P. L., Møller, N. C., Togo, P., \& Heitmann, B. L. (2011). Television viewing, food preferences, and food habits among children: a prospective epidemiological study. BMC Public Health, 11(1), 1-10.

Hart, R. A. (2013). Children's participation: The theory and practice of involving young citizens in community development and environmental care. Routledge.

King, G., Petrenchik, T., Dewit, D., McDougall, J., Hurley, P., \& Law, M. (2010). Out-ofschool time activity participation profiles of children with physical disabilities: a cluster analysis. Child: care, health and development, 36(5), 726-741.

Martin, D., Bat-Chava, Y., Lalwani, A., \& Waltzman, S. B. (2011). Peer relationships of deaf children with cochlear implants: Predictors of peer entry and peer interaction success. Journal of Deaf Studies and Deaf Education, 16(1), 108-120.

McKown, C., Gumbiner, L. M., Russo, N. M., \& Lipton, M. (2009). Social-emotional learning skill, self-regulation, and social competence in typically developing and clinicreferred children. Journal of Clinical Child \& Adolescent Psychology, 38(6), 858-871.

Ollendick, T. H., Jarrett, M. A., Grills-Taquechel, A. E., Hovey, L. D., \& Wolff, J. C. (2008). Comorbidity as a predictor and moderator of treatment outcome in youth with anxiety, affective, attention deficit/hyperactivity disorder, and oppositional/conduct disorders. Clinical Psychology Review, 28(8), 1447-1471.

Owen-DeSchryver, J. S., Carr, E. G., Cale, S. I., \& Blakeley-Smith, A. (2008). Promoting social interactions between students with autism spectrum disorders and their peers in inclusive school settings. Focus on Autism and other developmental disabilities, 23(1), 15-28. 
Powell, B., Cooper, G., Hoffman, K., \& Marvin, B. (2013). The circle of security intervention: Enhancing attachment in early parent-child relationships. Guilford publications.

Raghavendra, P., Olsson, C., Sampson, J., McInerney, R., \& Connell, T. (2012). School participation and social networks of children with complex communication needs, physical disabilities, and typically developing peers. Augmentative and alternative communication, 28(1), 33-43.

Roser, C. (2016). Faster, better, cheaper in the history of manufacturing: from the stone age to lean manufacturing and beyond. CRC Press.

Rubin, K. H., Coplan, R., Chen, X., Bowker, J., \& McDonald, K. L. (2013). Peer relationships in childhood. In Social and personality development (pp. 317-368). Psychology Press.

Rudolph, K. D. (2010). Implicit theories of peer relationships. Social Development, 19(1), 113129. 